\title{
BENCHMARK EVALUATION OF REACTIVITY EFFECTS AND REACTIVITY COEFFICIENTS IN THE MOLTEN SALT REACTOR EXPERIMENT
}

\author{
Dan Shen ${ }^{1}$, Massimiliano Fratoni ${ }^{1}$ \\ ${ }^{1}$ University of California, Berkeley \\ Department of Nuclear Engineering, Berkeley CA 94720-1730 \\ danshen.echo@berkeley.edu, maxfratoni@berkeley.edu
}

\begin{abstract}
A set of benchmarks based on the experimental data from the Molten Salt Reactor Experiment (MSRE) is being compiled as part of International Reactor Physics Experiments Evaluation Project (IRPhEP). The initial benchmark that will be available in the 2019 edition of the IRPhEP handbook covers the first zero-power criticality experiment. Follow up benchmarks are under development based on the series of control rod calibration experiments performed at the MSRE, which consisted in progressive addition of a small amount $(85 \mathrm{~g})$ of ${ }^{235} \mathrm{U}$ in the salt followed by the insertion of the control rods acts to compensate for the excess reactivity insertion. Multiple reactivity effects and coefficients measurements are included in the benchmark: differential worth of a control rod, reactivity equivalent of ${ }^{235} U$ addition, control rod bank worth, reactivity effect of fuel circulation, isothermal temperature coefficient and fuel temperature coefficient. An uncertainty of $2 \%$ is attributed to the reported reactivity measurements from experimenters and it was believed that the uncertainty of reactor period measurement contributed the most of the experimental uncertainty. An additional 2\% uncertainty was added to all reactivity measurements to represent the uncertainty for the correction factor applied to pull all the measurements on the same uranium concentration and this uncertainty was reasonably inferred by evaluating this factor on the MSRE benchmark model. The calculated reactivity equivalent of ${ }^{235} U$ additions $(0.2228 \pm 0.0014$, represented as the change of reactivity over the relative change of ${ }^{235} \mathrm{U}$ mass in loop) matches well with the experiment value $(0.223 \pm 0.006)$. Most of other calculations, including the control rod bank worth, reactivity effects of fuel circulation and isothermal and fuel temperature coefficients fall within one standard deviation from the experimental values as well.
\end{abstract}

KEYWORDS: MSRE, molten salt fuel, control rod worth, reactivity effect

\section{INTRODUCTION}

The Molten Salt Reactor Experiment (MSRE) was built at the Oak Ridge National Laboratory (ORNL) and was operated between 1965 and 1969, aiming to demonstrate key features of the molten salt liquid fuel reactor concept and to prove the practicality of the molten salt reactor (MSR) technology. This was the first large-scale, long-term, high-temperature testing performed for a liquid fuel salt, graphite moderator and new nickel-based alloys in a reactor environment $[1,2]$. The MSRE design and experiments were accurately documented in a large number of reports, further making it a good candidate to be an MSR-related benchmark for computational codes validation in order to support the licensing process and commercialization of MSRs. 
The University of California, Berkeley and the Oak Ridge National Laboratory (ORNL) have collaborated to create the first MSR-related benchmark based on the MSRE for the International Reactor Physics Experiment Evaluation Project (IRPhEP) handbook, available in the 2019 edition. This initial MSRE benchmark covers the first zero-power criticality experiment with ${ }^{235} \mathrm{U}$ and it provides a fully-detailed, peerreviewed benchmark model. Additional MSRE benchmarks have been developed based on the series of control rod calibration experiments performed at the MSRE following the first zero-power critical experiment in June 1965 [1]. This paper describes the evaluation of the control rod calibration experiments on MSRE at zero power, including differential worth of control rod, reactivity equivalent of ${ }^{235} \mathrm{U}$ addition, control rod bank worth, reactivity effects of fuel circulation, isothermal temperature coefficient and fuel temperature coefficient measurements.

\section{REACTOR CORE DESCRIPTION}

The MSRE reactor vessel is described in detail in Reference 2. A brief summary is provided here. The reactor vessel has an inner diameter of $147.32 \mathrm{~cm}$ and a height of $233.90 \mathrm{~cm}$. The fuel salt enters the flow distributor at the top of the vessel through the fuel inlet, arranged tangentially to the vessel. The flow distributor is half-circular in cross section and its inside radius is $10.16 \mathrm{~cm}$. After passing the distributor, the fuel is distributed evenly around the circumference of the vessel and then flows turbulently downward in a spiral path through a $2.54-\mathrm{cm}$-wide annulus between the vessel wall and the core can. The salt loses its rotational motion in the 48 straightening vanes in the lower plenum and flows upward through the graphite matrix in the core can. All metal components in contact with salt are made of INOR-8, a special high-nickel and molybdenum alloy. The fuel salt composition is $64.88^{7} \mathrm{LiF}^{2}-29.27 \mathrm{BeF}_{2}-5.06 \mathrm{ZrF}_{4}-0.79 \mathrm{UF}_{4}$ (expressed as molar percent) at the time of criticality. The ${ }^{7} \mathrm{Li}$ enrichment was $99.995 \%$. The core is made up of a graphite lattice, an assembly of vertical stringers with a $5.08 \mathrm{~cm}$ by $5.08 \mathrm{~cm}$ cross section (see Figure 1). Fissioning occurs when the fuel salt flows through the channels that are formed by grooves in the sides on the stringers. These channels are $1.016 \mathrm{~cm}$ by $3.048 \mathrm{~cm}$ with round corners of radius $0.508 \mathrm{~cm}$. The graphite core stringers are $170.03 \mathrm{~cm}$ long and are mounted in a vertical close-packed array. There are a total of 1140 equivalent full-size passages, counting fractional sizes. The dimensions of the flow channel were chosen to provide a passage that would not be blocked by small pieces of graphite and also to obtain a nearly optimum fuel-tographite ratio in the core. The upper surface of the graphite stringer is tapered such that no salt will stand on them after a reactor drain.

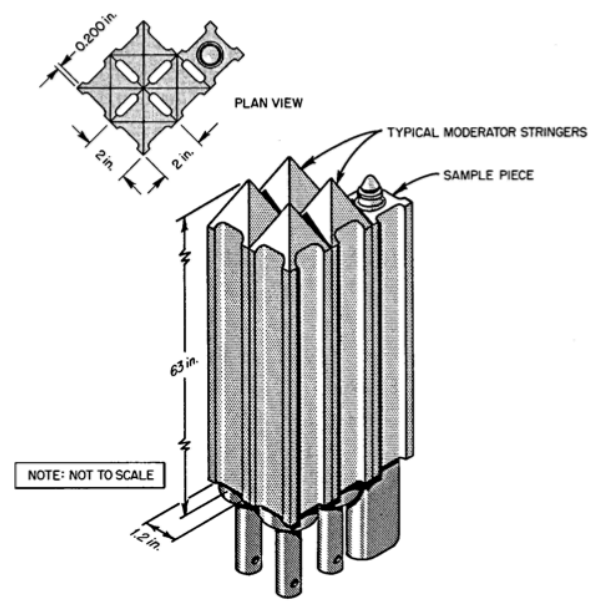

Figure 1. Dimensions and Arrangement of the Graphite Stringers [2].

Three control rod thimbles are arranged near the center of the core in place of graphite stringers as shown in Figure 2. The thimbles have a $5.08-\mathrm{cm}$ outer diameter and $0.1651-\mathrm{cm}$ thick wall. The control rods are 
segmented to provide the flexibility to pass through the bends in the control rod thimbles. The poison material, a mixture of $70 \mathrm{wt} . \% \mathrm{Gd}_{2} \mathrm{O}_{3}$ and $30 \mathrm{wt} . \% \mathrm{Al}_{2} \mathrm{O}_{3}$, is in the form of hollow cylinder canned in Inconel shell as shown in Figure 2. The control rod segments are threaded on a helically wound, stainless steel hose. There are also three graphite and INOR-8 sample baskets mounted vertically near the center region because one of the important objectives of the MSRE was to investigate the behavior of INOR-8 and unclad graphite in the reactor environment. Each basket contains four $0.635-\mathrm{cm}$-diameter samples of INOR8 and five graphite sample bars, $0.635 \mathrm{~cm}$ by $1.1938 \mathrm{~cm}$.
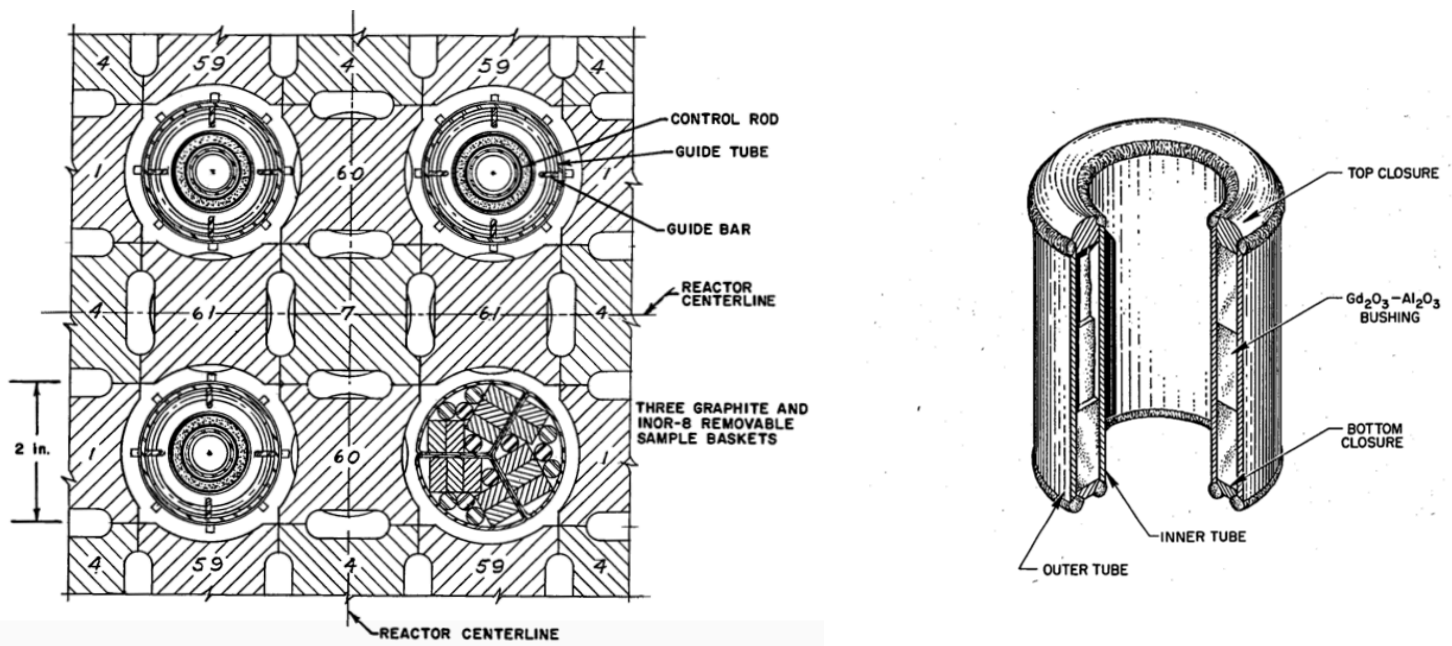

Figure 2. Control Rod and Sample Basket [2] (left); cutaway of a Control Element [3] (right).

The reactor vessel is installed in a stainless-steel thermal shield that supports the vessel and forms the outer wall of the reactor furnace as shown in Figure 3. The shield has an approximate outer diameter of $317.5 \mathrm{~cm}$ and an inner diameter of $236.22 \mathrm{~cm}$.

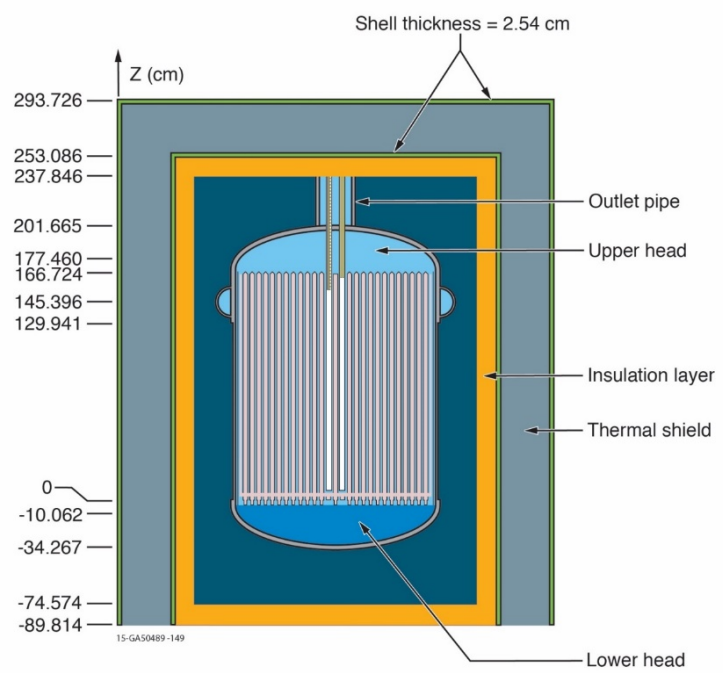

Figure 3. Vertical Cross Section of the MSRE Model at 911 K. Credit: David R. Sharp, Idaho National Laboratory.

\section{REACTIVITY EFFECTS AND REACTIVITY COEFFICIENTS MEASUREMENTS}

Following the initial zero-power criticality experiment conducted on the MSRE in June, a series of control rod calibration experiments measuring reactivity effects were performed by ORNL [1]. The general method 
of increasing the uranium concentration in the fuel salt was to add $85 \mathrm{~g}{ }^{235} \mathrm{U}$ in a capsule at a time through the sampler-enricher. The insertion of the regulating control rod (rod No. 1, the top right rod in Figure 2) always acts to follow and compensate for any net excess reactivity from the additions of uranium or any change of the core configuration. Figure 4 qualitatively depicts the procedure of these control rod calibration experiments. Each curve in Figure 4 is a qualitative graphical description of the change in the static reactivity as a function of regulating rod (rod No. 1) position and various curves represent different ${ }^{235} \mathrm{U}$ loadings, increasing in the direction shown by the arrow. The static reactivity $\rho_{s}$, corresponding to each specific rod position and ${ }^{235} \mathrm{U}$ loading is defined by the following equation:

$$
\rho_{s}=\frac{v-v_{c}}{v}
$$

where $v$ is the actual number of neutrons emitted per fission, and $v_{c}$ is the fictitious value for which the reactor with the specified rod position and material composition, and with the fuel stationary, would be just critical. An equivalent expression is:

$$
\rho_{s}=\frac{k_{e f f}-1}{k_{e f f}}
$$

where $k_{\text {eff }}$ is the effective multiplication constant of the reactor.

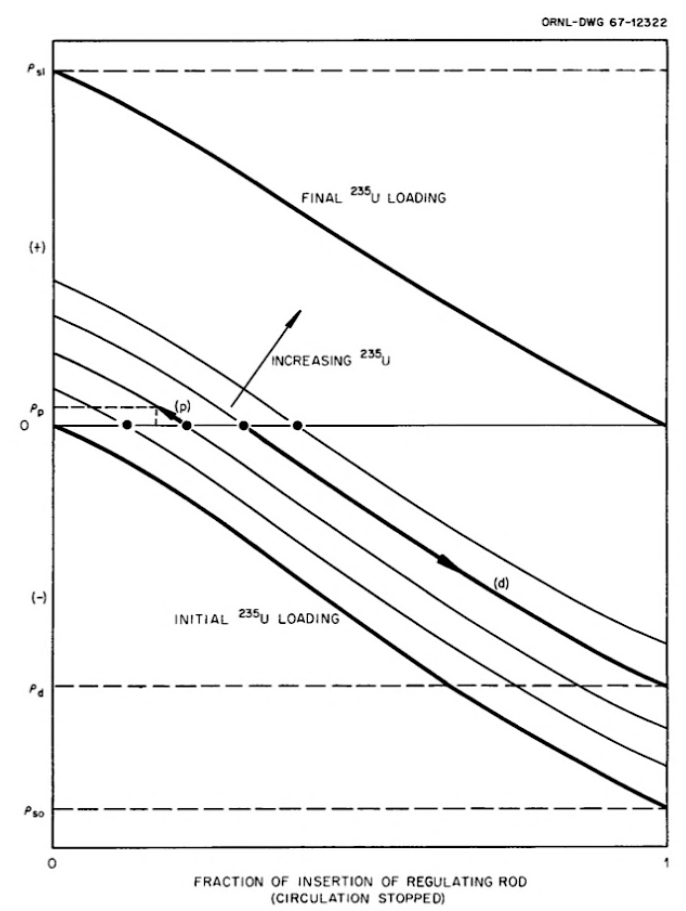

Figure 4. Graphical Description of Control Rod Calibration Experiments [1].

A typical measurement of the stable period in Figure 4 corresponds to an upward motion from the critical position (marked $p$ ). The measured change in reactivity, $\rho_{p}$, is divided by the change in rod motion, and this differential worth is ascribed to the mean position. A rod-drop experiment is indicated in Figure 4 by the segment marked $(d)$, extending from the initial critical position to the fully inserted position. The purpose of this experiment is to measure the negative reactivity inserted by the drop, marked $\rho_{d}$.

The reactivity worth of the rods is affected by the ${ }^{235} U$ concentration in the core. Since the ${ }^{235} U$ loading was continually being increased during the course of these experiments, theoretical corrections have been applied to these measurements to put them all on the basis of one ${ }^{235} \mathrm{U}$ concentration, arbitrarily chosen as 


\section{Physics of Reactors Transition to a Scalable Nuclear Future}

the initial critical concentration $\left(65.25 \mathrm{~kg}{ }^{235} \mathrm{U}\right.$ in loop) at the beginning of the rod calibration experiments. The basic assumption here is that the shape of integral worth vs position curve for control rods is unaffected by ${ }^{235} \mathrm{U}$ concentration. The approximate correction factors which were applied to the rod sensitivity measurements increase linearly with ${ }^{235} \mathrm{U}$ concentration, up to 1.087 for the measurements made near the final concentration which means $71.71 \mathrm{~kg}{ }^{235} \mathrm{U}$ in loop.

The isothermal temperature coefficient and fuel temperature coefficient were measured based on the results of control rod calibration experiments. At three fixed ${ }^{235} \mathrm{U}$ concentrations, the reactor system temperature was varied slowly (about $15^{\circ} \mathrm{F} / \mathrm{h}$ ) by adjusting electric heaters while the critical position of the regulating rod was observed. The change in critical position of the regulating rod was converted to reactivity by use of the rod calibration results. This experiment gave the overall temperature coefficient, that is, the sum of fuel and graphite coefficients. These experiments were performed with fuel circulating. An attempt was made to separate the fuel (rapid) and graphite (sluggish) temperature coefficients by an experiment in which the fuel was kept in circulation and the coolant loop was stagnant. After heating the stagnant coolant salt about $20^{\circ} \mathrm{F}$ hotter than the fuel salt, the coolant pump was started, introducing a hot slug of fuel into the heat exchanger and subsequently into the core. In this test, then, the change in reactivity was due entirely to the change in fuel temperature.

\section{COMPUTATIONAL MODEL}

The fully detailed benchmark model for the MSRE first criticality experiment was utilized to analyze the reactivity effects and reactivity coefficients measurement (see Figure 3). In this benchmark model, the dimensions for graphite lattice, control rod thimbles, sample baskets, reactor vessel shell, flow distributor and thermal shield are modeled according to the design data or blueprints. However, the control rod calibration experiments were operated at $922 \mathrm{~K}$, not $911 \mathrm{~K}$ for the criticality experiment. All the dimensions of the benchmark model are hot dimensions (at $922 \mathrm{~K}$ ) by performing a thermal expansion of graphite and metal components in the reactor vessel from $68^{\circ} \mathrm{F}\left(293 \mathrm{~K}\right.$, room temperature) to $1200^{\circ} \mathrm{F}(922 \mathrm{~K})$.

The MSRE was modeled with the Monte Carlo code Serpent2 [4] (version 2.1.30), using the ENDF/B-VII.1 cross-section library. The temperature for cross section library is set at $900 \mathrm{~K}$ and it is pre-processed for Doppler broadened to $922 \mathrm{~K}$ by Serpent2. The thermal scattering library is based on ENDF/B-VII.1 for C in graphite (with temperature $922 \mathrm{~K}$ in the core and $305 \mathrm{~K}$ in the thermal shield) and $\mathrm{H}$ in water (with temperature $305 \mathrm{~K}$ in the thermal shield). For thermal scattering Serpent 2 applies temperature interpolation among the two closest temperature libraries.

To evaluate the reactivity loss due to fuel circulation, the benchmark model was slightly modified. The distributor was removed, the shape of the vessel was changed to a cylinder while keeping the volume of the upper head and lower head unchanged and the tapered region on top of the graphite stringer was removed as well to support the assumption of a flat velocity profile for the salt through each region. The main impact of salt circulation on reactivity is due to a change in the effective delayed neutron fraction $\left(\beta_{\text {eff }}\right)$. In order to obtain $\beta_{\text {eff }}$ for the circulating case, the following considerations are made. The ratio between $\beta_{\text {eff }}$ with circulating and stationary salt can be determined as follows:

$$
\frac{\beta_{\text {eff }}^{c}}{\beta_{\text {eff }}^{S}}=\frac{\int_{\text {core }} D^{c}(\vec{r}) I^{c}(\vec{r}) d V}{\int_{\text {core }} D^{S}(\vec{r}) I^{S}(\vec{r}) d V}
$$

where $D(\vec{r})$ is the probability density of delayed neutron precursors (DNPs) to decay in position $\vec{r}$, and $I(\vec{r})$ is the spatial dependence of the neutron importance. $\beta_{\text {eff }}$ can be calculated through Eq. (4) where $k_{p}$ is the multiplication factor for prompt neutrons only, which is the same in the circulating and stationary salt case: 


$$
\beta_{e f f} \cong 1-\frac{k_{p}}{k_{e f f}}
$$

Given $k_{\text {eff }}$ and $\beta_{\text {eff }}$ in the stationary salt case, $k_{\text {eff }}$ in circulating case is obtained combining Eq. (3) and Eq. (4) thus the reactivity loss due to fuel circulation can be quantified by comparing $k_{\text {eff }}$ in circulating case and stationary case. $D(\vec{r})$ and $I(\vec{r})$ for circulating and stationary salt cases are calculated on the simplified MSRE benchmark model. The fuel salt speed was measured to be $6.11 \mathrm{~cm} / \mathrm{s}$ in the lower head, 17.71 $\mathrm{cm} / \mathrm{s}$ in the graphite lattice region and $6.12 \mathrm{~cm} / \mathrm{s}$ in the upper head. The time spent outside of the core is $32 \%$ of the total required to complete a loop $(25.2 \mathrm{~s})$.

\section{UNCERTAINTY EVALUATION}

An uncertainty of $2 \%$ is attributed to the reported reactivity effects from ORNL. It was believed that the experimental measurement uncertainty was significantly larger than the computation process uncertainty and the uncertainty of reactor period measurement contributed the most to the experimental uncertainty. Also, there's an uncertainty caused by the correction factors which were applied to the rod sensitivity measurements to pull the measurements all on the basis of one ${ }^{235} \mathrm{U}$ concentration. This correction factor was calculated by ORNL and now checked on the MSRE benchmark model. The reactivity change of rod No. 1 between fully withdrawn and fully inserted positions was evaluated with various ${ }^{235} \mathrm{U}$ loadings in loop and the correction factor for a certain ${ }^{235} \mathrm{U}$ concentration was defined as follows:

$$
c f(x)=\frac{\rho_{1}\left(x_{0}\right)-\rho_{0}\left(x_{0}\right)}{\rho_{1}(x)-\rho_{0}(x)}
$$

where $x$ is the ${ }^{235} \mathrm{U}$ loadings in loop, $x_{0}$ is $65.25 \mathrm{~kg}, \rho_{l}(x)$ is the reactivity with rod No. 1 fully withdrawn and $\rho_{0}(x)$ is the reactivity with rod No.1 fully inserted into the core. It was found that the calculated correction factor varies almost linearly with the ${ }^{235} \mathrm{U}$ concentration as shown in Figure 5. The largest deviation from the correction factors calculated by the MSRE benchmark model to those provided by ORNL, applied for a certain ${ }^{235} \mathrm{U}$ level, was found to be less than $2 \%$. So, the uncertainty due to the applied correction factor was assumed to be $2 \%$. No significant bias or systematic error was observed for the correction factor applied on the measurements. The uncertainty of rod worth measurements is now the square root of the sum of the squares of the experimental uncertainty and the uncertainty in the correction factor, which is $2.83 \%$.

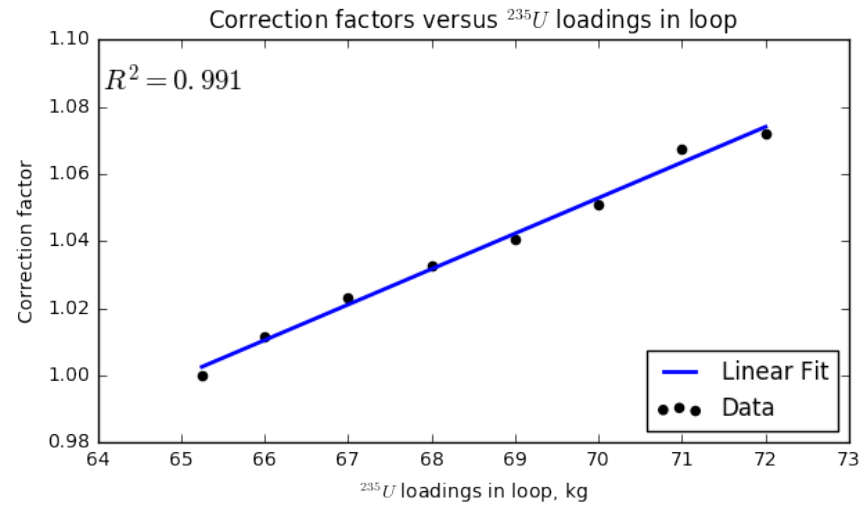

Figure 5. Correction Factor for Different ${ }^{235} \mathrm{U}$ Loadings in Loop.

As stated before, the basic assumption supporting the application of correction factor is that the shape of integral worth vs position curve for control rods is unaffected by ${ }^{235} \mathrm{U}$ concentration. This assumption was checked on the MSRE benchmark model. The plot of normalized rod worth $f(z)$ vs normalized rod position 
$z$ with three different ${ }^{235} \mathrm{U}$ concentrations is shown in Figure 6, where $z$ measures the height of rods above the lower limit and this curve was normalized to zero at lower limit $(z=0)$ and to unity at the upper limit $(z=1)$. The three curves in Figure 6 differ very little, demonstrating the feasibility of this assumption.

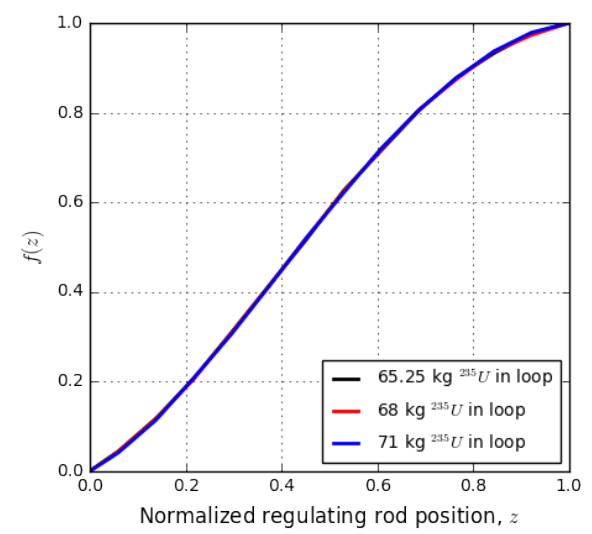

Figure 6. Regulating Curve of Regulating Control Rod in the Presence of (a) $65.25 \mathrm{~kg}^{235} \mathrm{U}$ in Loop, (b) $68 \mathrm{~kg}{ }^{235} \mathrm{U}$ in Loop and (c) $71 \mathrm{~kg}{ }^{235} \mathrm{U}$ in Loop.

\section{RESULTS}

\subsection{Differential Control Rod Worth}

For the differential control rod worth evaluation rod No. 1 was moved from the fully withdrawn position to the bottom of the control rod thimble while other two rods were held fully withdrawn. The reactivity of the core with rod No. 1 at 51 in, 47 in, 43 in, 39 in, 35 in, 31 in, 27 in, 23 in, 19 in, 15 in, 11 in, 7 in, 4 in, 3 in, 2 in, 0 in and -2 in was calculated and the integral worth and differential worth of rod No. 1 are shown in Figure 7. The calculated differential worth tends to be shifted to the left from the benchmark value overall and this shift led to the mismatch in the integral worth curve as well. The higher calculated differential worth at 0 inch (see the right figure of Figure 7) potentially indicates that the rod in the model was not inserted low enough at its fully inserted position. The initial fully withdrawn position of the control rods was obtained indirectly since, as stated before, the benchmark model was thermally expanded downward by assumption. If we artificially lower the upper limit of all rods by $10 \mathrm{~cm}$, which means inserting all rods $10 \mathrm{~cm}$ more at the beginning, the mismatch in both the integral and differential worth could be corrected in the right direction as shown in Figure 8. This phenomenon indicates the need to further investigate the initial position of all rods at room temperature and the thermal expansion mechanism of them.
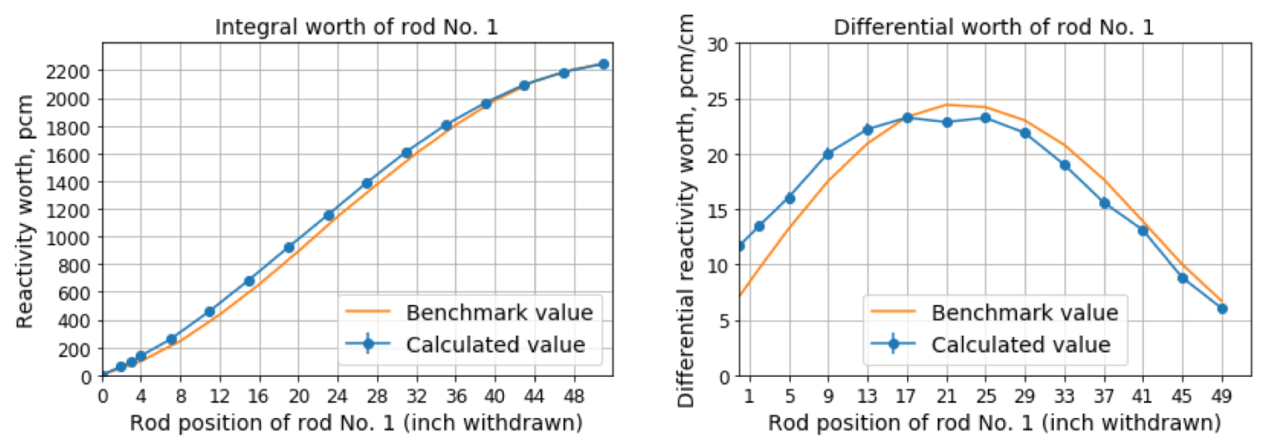

Figure 7. Integral Worth (Left) and Differential Worth (Right) of Rod No. 1. 

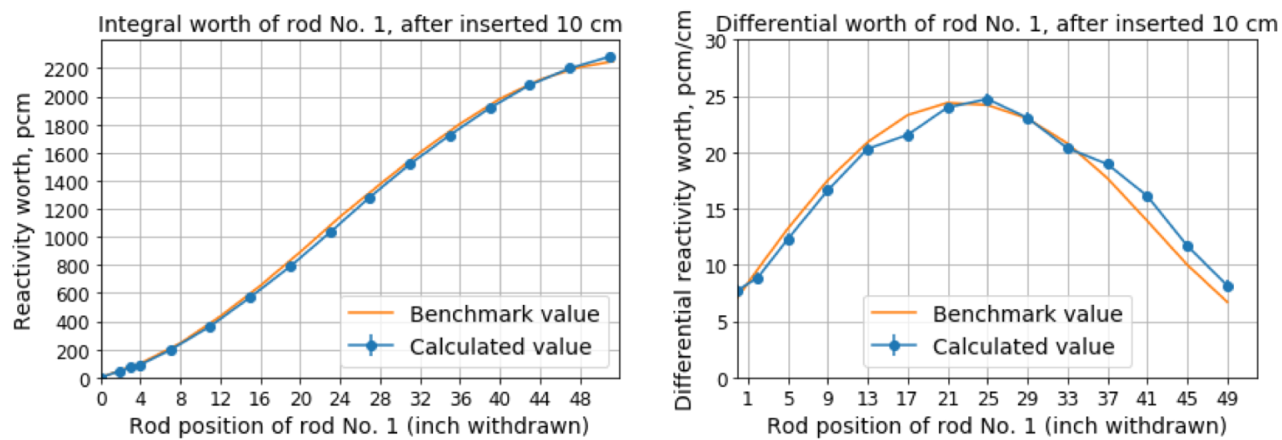

Figure 8. Integral Worth (Left) and Differential Worth (Right) of Rod No. 1 after Inserting All Control Rods $10 \mathrm{~cm}$ at the Beginning Positions.

\subsection{Reactivity Equivalent of ${ }^{235} \mathrm{U}$ Additions}

Reactivity for cases with ${ }^{235} \mathrm{U}$ loadings of $65.25 \mathrm{~kg}, 66 \mathrm{~kg}, 67 \mathrm{~kg}, 68 \mathrm{~kg}, 69 \mathrm{~kg}, 70 \mathrm{~kg}, 71 \mathrm{~kg}$ and $72 \mathrm{~kg}$ in the loop was calculated, while the core configuration is set as all control rods withdrawn to their upper limit. The results are plotted in Figure 9. The average value of reactivity equivalent of ${ }^{235} \mathrm{U}$ additions are obtained as the linear regression coefficient as shown in Figure 9. The calculated value of the reactivity equivalent of ${ }^{235} \mathrm{U}$ additions is provided in Table I. The uncertainty of the calculated value is from Monte Carlo calculations and the relative uncertainty of the benchmark value is $2.83 \%$, mainly from rod worth measurement as explained before. The calculated value and the benchmark value are in good agreement

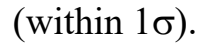

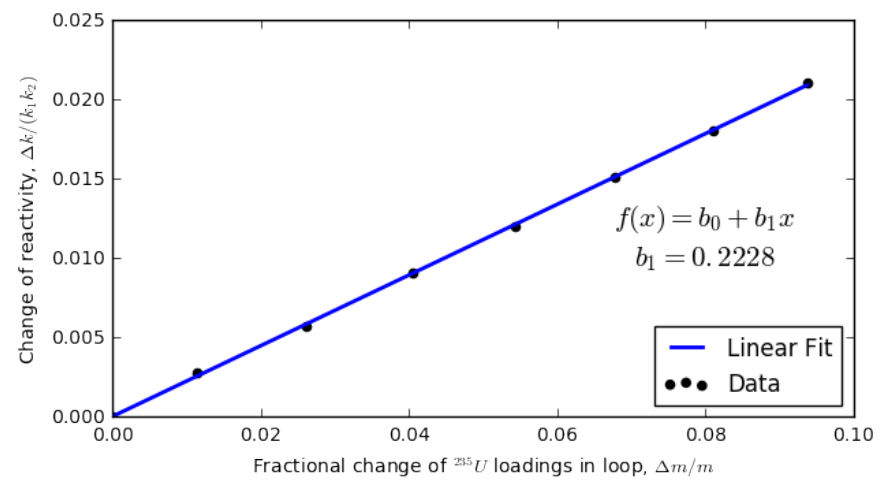

Figure 9. Effect of ${ }^{235} \mathrm{U}$ Mass on Reactivity.

Table I. Reactivity equivalent of ${ }^{235} \mathrm{U}$ additions, $(\delta \rho) /(\delta \mathrm{m} / \mathrm{m})$

\begin{tabular}{|c|c|c|}
\hline Calculated value $\pm \sigma$ & Benchmark value $\pm \sigma$ & $\mathrm{C} / \mathrm{E} \pm \sigma$ \\
\hline $0.2228 \pm 0.0014$ & $0.223 \pm 0.006$ & $0.999 \pm 0.029$ \\
\hline
\end{tabular}

\subsection{Control Rod Bank Worth}

The control rod bank worth from rod bank No. 1 and No. 2 and rod bank for all three rods were calculated from the change of reactivity with rod bank fully withdrawn (51 in withdrawn) and fully inserted (0 in withdrawn) at three certain ${ }^{235} \mathrm{U}$ loading level. The calculated values of the control rod bank worth are 
provided in Table II. The calculated values and the benchmark values are in good agreement (within $1 \sigma$ for 5 cases and within $2 \sigma$ for only 1 case).

Table II. Control rod bank worth

\begin{tabular}{|l|c|c|c|c|c|}
\hline Case & Rod group & $\begin{array}{c}{ }^{235} \mathrm{U} \text { in } \\
\text { loop, } \mathrm{kg}\end{array}$ & $\begin{array}{c}\text { Calculated value } \pm \sigma, \\
\mathrm{pcm}\end{array}$ & $\begin{array}{c}\text { Benchmark value } \pm \sigma, \\
\mathrm{pcm}\end{array}$ & $\mathrm{C} / \mathrm{E} \pm \sigma$ \\
\hline 1 & $1-2$ & 67.94 & $4042 \pm 14$ & $4099 \pm 116$ & $0.99 \pm 0.03$ \\
\hline 2 & $1-2$ & 69.94 & $3945 \pm 13$ & $3975 \pm 112$ & $0.99 \pm 0.03$ \\
\hline 3 & $1-2$ & 71.71 & $3870 \pm 13$ & $4075 \pm 115$ & $0.95 \pm 0.03$ \\
\hline 4 & $1-2-3$ & 67.94 & $5653 \pm 14$ & $5596 \pm 158$ & $1.01 \pm 0.03$ \\
\hline 5 & $1-2-3$ & 69.94 & $5526 \pm 13$ & $5611 \pm 159$ & $0.98 \pm 0.03$ \\
\hline 6 & $1-2-3$ & 71.71 & $5463 \pm 13$ & $5570 \pm 158$ & $0.98 \pm 0.03$ \\
\hline
\end{tabular}

\subsection{Reactivity Effect of Fuel Circulation}

The calculated value for the reactivity effect of fuel circulation is provided in Table III. The calculated value shows good agreement with the benchmark value (within $1 \sigma$ ).

Table III. Reactivity effects of fuel circulation

\begin{tabular}{|c|c|c|}
\hline $\begin{array}{c}\text { Calculated } \\
\text { value } \pm \sigma, \mathrm{pcm}\end{array}$ & $\begin{array}{c}\text { Benchmark } \\
\text { value } \pm \sigma, \mathrm{pcm}\end{array}$ & $\mathrm{C} / \mathrm{E} \pm \sigma$ \\
\hline $222 \pm 10$ & $212 \pm 6$ & $1.05 \pm 0.06$ \\
\hline
\end{tabular}

\subsection{Isothermal Temperature Coefficient}

The benchmark model temperature is $922 \mathrm{~K}$ and it was varied $\pm 50 \mathrm{~K}$ at three various ${ }^{235} \mathrm{U}$ loadings in the loop. The change in the reactor core geometry was considered with the change of temperature according the thermal expansion coefficients of materials. Both the temperature and density changes were considered for all materials inside the reactor vessel. All control rods were fully withdrawn. The calculated values for isothermal temperature coefficients at three ${ }^{235} \mathrm{U}$ loadings are provided in Table IV. The calculated values are slightly smaller than the benchmark value but they agree within $1 \sigma$.

Table IV. Isothermal temperature coefficient

\begin{tabular}{|l|c|c|c|}
\hline${ }^{235} \mathrm{U}$ in loop, $\mathrm{kg}$ & Calculated value $\pm \sigma,{ }^{\circ} \mathrm{F}^{-1}$ & Benchmark value $\pm \sigma,{ }^{\circ} \mathrm{F}^{-1}$ & $\mathrm{C} / \mathrm{E} \pm \sigma$ \\
\hline 67.86 & $-(6.95 \pm 0.13) \times 10^{-5}$ & $-(7.45 \pm 0.85) \times 10^{-5}$ & $0.93 \pm 0.11$ \\
\hline 69.85 & $-(6.69 \pm 0.13) \times 10^{-5}$ & $-(7.24 \pm 0.83) \times 10^{-5}$ & $0.92 \pm 0.11$ \\
\hline 71.71 & $-(6.56 \pm 0.13) \times 10^{-5}$ & $-(7.3 \pm 0.83) \times 10^{-5}$ & $0.90 \pm 0.10$ \\
\hline
\end{tabular}

\subsection{Fuel Temperature Coefficient}

The benchmark model temperature is $922 \mathrm{~K}$ and the fuel salt temperature was varied $\pm 50 \mathrm{~K}$. The density of the fuel salt was adjusted with the change of temperature. All three control rods were fully withdrawn. The 
${ }^{235} \mathrm{U}$ loading is the initial critical amount. The calculated value for fuel temperature coefficient is provided in Table V. The calculated value is slightly smaller than the benchmark value but they agree within $1 \sigma$.

Table V. Fuel temperature coefficient

\begin{tabular}{|c|c|c|}
\hline Calculated value $\pm \sigma,{ }^{\circ} \mathrm{F}^{-1}$ & Benchmark value $\pm \sigma,{ }^{\circ} \mathrm{F}^{-1}$ & $\mathrm{C} / \mathrm{E} \pm \sigma$ \\
\hline$-(4.30 \pm 0.14) \times 10^{-5}$ & $-(4.7 \pm 0.7) \times 10^{-5}$ & $0.92 \pm 0.14$ \\
\hline
\end{tabular}

\section{CONCLUSIONS}

Following the initial MSRE benchmark for the 2019 edition of the IRPhEP handbook, a new set of MSRE benchmarks was created based on the series of control rod calibration experiments performed at the MSRE after the first zero-power critical experiment in June 1965. During the control rod calibration experiment, the general method of increasing the uranium concentration in the fuel salt was to add $85 \mathrm{~g}^{235} \mathrm{U}$ in a capsule at a time through the sampler-enricher. The insertion of the regulating control rod always acts to follow and compensate for any net excess reactivity from the additions of uranium. The fully-detailed benchmark model for the MSRE first criticality experiment, using Monte Carlo code Serpent2, was utilized to analyze the reactivity effects and reactivity coefficients measurement. An uncertainty of $2 \%$ is attributed to the reported reactivity measurements from experimenters and it was believed that the uncertainty of reactor period measurement contributed the most of the experimental uncertainty. An additional $2 \%$ uncertainty was added to all reactivity measurements to represent the uncertainty for the correction factor applied to pull all the measurements on the same uranium concentration and this uncertainty was reasonably inferred by evaluating this factor on the MSRE benchmark model. The calculated reactivity equivalent of ${ }^{235} \mathrm{U}$ additions $\left(0.2228 \pm 0.0014\right.$, represented as the change of reactivity over the relative change of ${ }^{235} \mathrm{U}$ mass in loop) matches well with the experiment value $(0.223 \pm 0.006)$. Most of other calculations, including the control rod bank worth, reactivity effects of fuel circulation and isothermal and fuel temperature coefficients fall within one standard deviation from the experimental values as well. This follow up benchmark specification is expected to be included in the IRPhEP handbook in the next two years.

\section{ACKNOWLEDGMENTS}

This research is being performed using funding received from the DOE Office of Nuclear Energy's Nuclear Energy University Program. This research used the Savio computational cluster resource provided by the Berkeley Research Computing program at the University of California, Berkeley (supported by the UC Berkeley Chancellor, Vice Chancellor for Research, and Chief Information Officer).

\section{REFERENCES}

1. B. E. Prince, et al, "Zero-Power Physics Experiments on the Molten-Salt Reactor Experiment," ORNL4233, Oak Ridge National Laboratory, Oak Ridge, Tennessee (1968).

2. R. C. Robertson, "MSRE Design and Operations Report Part I: Description of Reactor Design", ORNLTM-0728, Oak Ridge National Laboratory, Oak Ridge, Tennessee (1965).

3. G. M. Tolson and A. Taboada, "MSRE Control Elements: Manufacture, Inspection, Drawings, and Specifications", ORNL-4123, Oak Ridge National Laboratory, Oak Ridge, Tennessee (1967).

4. J. Leppänen, et al, "The Serpent Monte Carlo Code: Status, Development and Applications in 2013," Ann. Nucl. Energy, 82, pp. 142-150 (2015). 